\title{
The Effect of Curing Pressure and Duration on Mechanical Strength of Ultra- high Molecular Weight Polyethylene/High-Density Polyethylene Composite as An Alternative Material for Windmill Turbine
}

\author{
Febrianti Nurul Hidayah ${ }^{\left.1^{\star}\right)}$ and Johan Boss ${ }^{2)}$ \\ 1) Faculty of Industrial Engineering, Islamic University of Indonesia \\ 2) Teijin Aramid, Arnhem Netherlands \\ * febrianti.nurul.hidayah@uii.ac.id \\ DOI: https://doi.org/10.21107/rekayasa.v13i3.8703
}

\begin{abstract}
The use of steel in building or construction manufacture continues to decrease, owing in part to the sustainability and mechanical properties of fibers which have higher strength in minimum weight than steel. This preliminary study was defined to evaluate the mechanical properties of high-performance fibers, especially ultrahigh molecular weight polyethylene (UHMWPE), in terms of the composite to be the main material of windmill turbines. It was UHMWPE as reinforcement and high-density polyethylene (HDPE) as a matrix in this composite system. The composites were processed in a variety of pressure and duration (50 to 165 bar and 10 minutes to 48 hours). The mechanical strength was tested by 3-point bending tests to measure the interlaminar shear strength, shear modulus, and bending strength. The result showed a significant difference in properties of the composite which is higher pressure and longer duration obtained a higher value of mechanical strength.
\end{abstract}

Keywords: fibers, HDPE, composite, bending test, shear strenght

\section{INTRODUCTION}

In the field of technical textiles, composite is one of the interesting main topics in many studies. One of composite application is in building or construction. The study of Byrne (2000) stated that the industrial applications on composite have been developed and high in market consumption which includes wind blades and fuel tanks. This goes hand in hand with the target of the European Commission that wind energy should be one of the primaries of renewable energy resources, thus the production of wind blades must be also increasing (European Commission., 1997). The reason for choosing a composite as turbine blades, for wind, marine, or even helicopter blades, is because the composite materials have prominent relations of mass/resistance and mass/rigidity (Fung, 2000; Nachtane et al., 2020). Moreover, Verma et al. (2019) added that fiber-reinforced composites

Article History:

Received: Sept, 29 ${ }^{\text {th }}$ 2019; Accepted: Dec, $9^{\text {th }} 2019$

Rekayasa ISSN: 2502-5325 has been Accredited by Ristekdikti (Arjuna) Decree: No. 23/E/KPT/2019 August 8th, 2019 effective until 2023 are applied for blades due to their corrosion resistance and high strengths such as specific, stiffness, and fatigue strengths. Besides consideration in strengths, the composite application also benefits in cost because of the easiness of its installation due to its low weight (Leary et al., 2019).

The structure of composite in terms of turbine blades must also be considered. Ullah et al. (2020) explained the importance of composite blades' design that needs to have an integrity structure that can bear the load while prone to the wind gusts. Under such extreme wind gusts, the failure can be obtained especially in adhesive joints or delamination that are related to interlaminar shear strength (Overgaard et al., 2010). Furthermore, the study of Zuo et al. (2018) examined the damage types of composite blades are a fracture of fibers, cracking of the matrix,

\section{Cite this as:}

Hidayah, F.N \& Boss, J. (2020).The Effect of Curing Pressure and Duration on Mechanical Strenght of Ultra-high Molecular Weight Polyethylene/High-Density Polyethylene Composite as An Alternative Material for Windmill Turbine. Rekayasa, 13 (3), 219-224.

doi: https://doi.org/10.21107/rekayasa.v13i3.8703.

(C) 2020 Febrianti Nurul Hidayah \& Johan Boss 
plies delamination, and debonding of interface adhesive. Those failures can reduce the mechanical strength of composite significantly including compressive and stiffness (Ullah et al., 2020).

Composite materials that are commonly applied in wind turbines are carbon and glass fibers with epoxy resin as the matrix (Van der Zee et al., 2017; A. C. Young et al., 2017). Both experimental and theoretical methods have been conducted by some researchers to search the failure mechanism of the composite in wind turbines, but none of them investigated ultrahigh molecular weight polyethylene (UHMWPE) as the main material (Dai et al., 2010; Kim et al., 2012). UHMWPE is known as an alternative material to aramid for ballistic protection, but the number of sales is still lower below aramid (Byrne, 2000). One of the disadvantages of this fiber is its low melting point $\left(150{ }^{\circ} \mathrm{C}\right)$ while aramid is above $500^{\circ} \mathrm{C}$ (Scott, 2000). UHMWPE has been applied as part of windmill blades which being a surface foil of rotor blade since it has various advantages such abrasion and wears resistance while having chemical and dimensional stability (Theile \& Hoffmann, 2019).

An earlier study observed UHMWPE in windmill blade application has low adhesion to conventional adhesives such as epoxy resin because it is not suitable for direct bonding (Theile \& Hoffmann, 2019). Therefore, the use of thermoplastic resin is necessary. The advantage of thermoplastic resins in windmill blades is their low manufacturing cost due to its recyclability and room temperature cure (Murray et al., 2019; Ramirez-Tejeda et al., 2016). One of the thermoplastic resins is HDPE. Therefore, in this study UHMWPE as reinforcement will be constructed in a composite system with HDPE as its matrix. The reason is both materials are thermoplastic, thus the need of adhesive bonds for blade components could be eliminated because it can be manufactured by fusion welding thus the strength and reliability might increase (Murray et al., 2019)

Many studies have investigated the use of UHMWPE as reinforcement, but the matrix is limited to the epoxy matrix (Theile \& Hoffmann, 2019), which one of them is also conducted in the previous study of this research (Hidayah, 2019). The reports about UHMWPE/HDPE composite in terms of mechanical properties for windmill blades applications have generally been lacking. Therefore, the present investigation explores the possibility of using UHMWPE in HDPE matrix with a variation of pressure and duration of curing, to study the relation of the mechanical properties of the composite to the difference of curing treatments.

\section{METHOD}

The materials consisted of UHMWPE tapes as the reinforcement which were from Teijin Aramid B.V. (The Netherlands) and HDPE as the matrix. The sheets of UHMWPE and HDPE were plied until the thickness of approximately 4-5 mm. These plies were then cured at the temperature of $130^{\circ} \mathrm{C}$. The variations were pressure and duration of curing. The pressure values were 50 , 100, and 165 bar for 10 minutes, while the variation of time was set on 10 minutes, 24 hours, and 48 hours under 50 bar pressure. After curing, these samples were then cut by using the Eurolaser ${ }^{\circledR}$ cutter machine in different dimensions based on each test standard.

The mechanical tests were conducted in two types: interlaminar shear and bending tests where both of them applied in 3-point bending apparatus with $2 \mathrm{~mm} / \mathrm{min}$ loading speed. The standard for interlaminar shear was ASTM D2344 while the bending test was based on ASTM D790. The samples of interlaminar shear were in a spanto-depth ratio of 4:1 (ASTM International, 1995) and bending samples were $5 \mathrm{~mm}$ thickness and $13 \mathrm{~mm}$ width (ASTM International, 2003). The data from mechanical tests were then compared and calculated in one-way ANOVA to find out the differences between the samples, and measured in the Pearson correlation coefficient to observe the relationship.

\section{RESULTS AND DISCUSSION Bending Test}

The samples were measured in bending tests in terms of bending strength and bending modulus. According to ASTM International (2003), the bending strength (also known as flexural strength in brittle materials) is defined as the maximum stress of the sample's mid-point outer surface. On the other hand, they determined the bending modulus which is also mentioned as modulus of elasticity, is the ration between the stress and the corresponding strain 


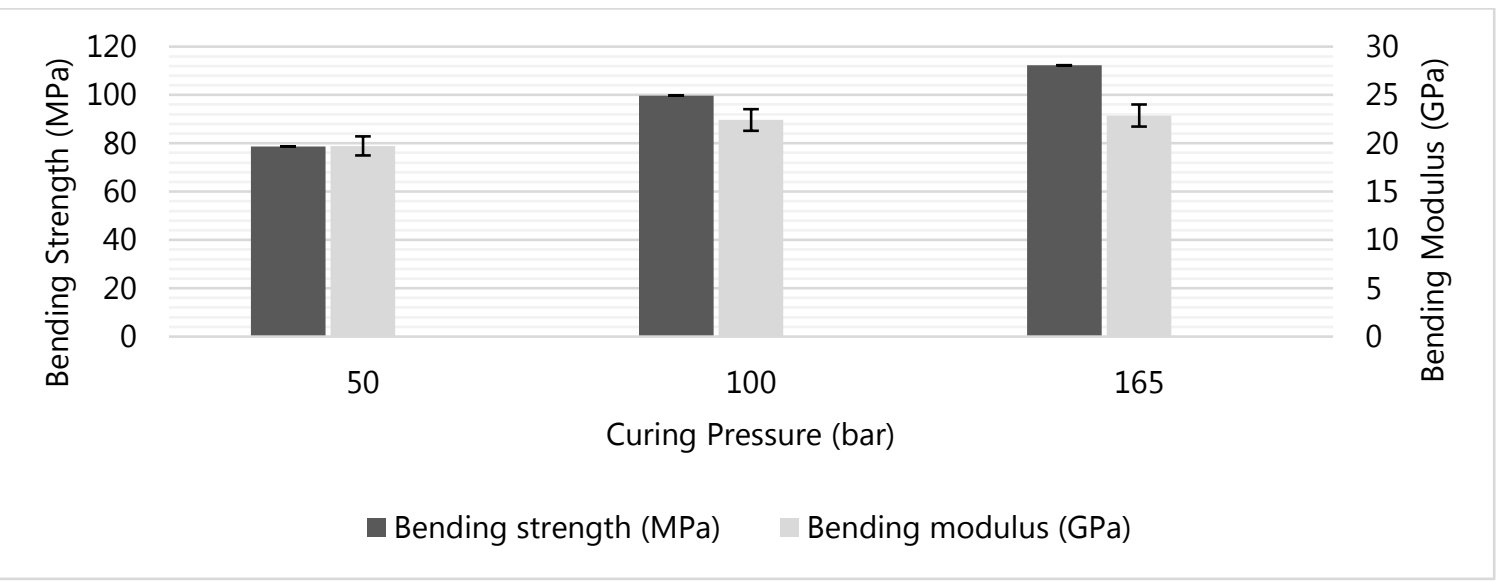

Figure 1. The Data of Bending Strength and Bending Modulus Of UHMWPE/HDPE Composite in Different Pressure With A Standard Of Deviation

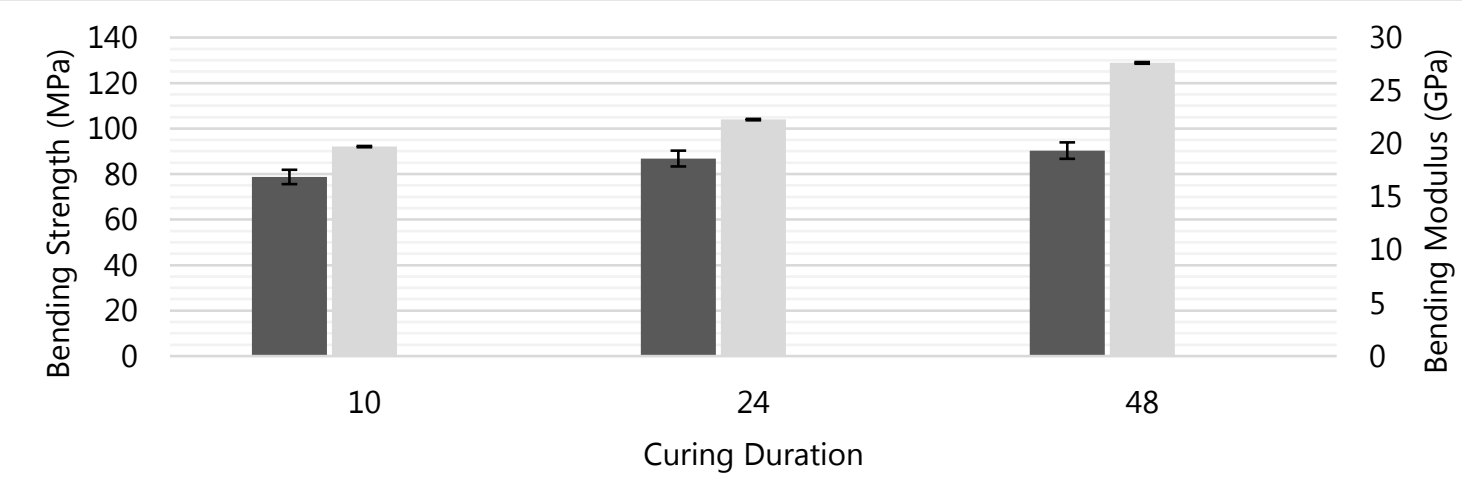

Bending strength (MPa) $\quad$ Bending modulus (GPa)

Figure 2. The data of bending strength and bending modulus of UHMWPE/HDPE composite in different duration with a standard of deviation

(ASTM International, 2003). The requirement of wind turbines needs strength and flexibility, thus it is essential to design an ultra-high-strength and flexible material to absorb extreme wind energy (Williamson, 1997). Therefore, the bending properties are discussed.

Based on Figure 1 and Figure 2, both pressure and duration of curing gave impact to the bending properties of the composites. For bending strength, the higher the pressure, the higher the bending strength. At a temperature of $130^{\circ} \mathrm{C}$ for 10 minutes, the results showed 78,72 $\mathrm{MPa}, 99,78 \mathrm{MPa}$, and $112,29 \mathrm{MPa}$ for 50,100 and 165 bar, respectively. Even though the bending modulus in Figure 1 rose, it was not as significant as the bending strength. On the other hand, the bending strength also increased in duration
(Figure 2). For 24 hours and 48 hours, the value went up from $86,82 \mathrm{MPa}$ to $90,31 \mathrm{MPa}$.

\section{ILSS Test}

The interlaminar shear strength is prominent in the composite system. Based on ASTM D2344, the interlaminar shear behavior is useful for controlling the quality of the composite whilst also applicable for research that concerns with inter-plies strength (ASTM International, 1995). The interlaminar shear test also proposed to evaluate the character of the delamination failure of the composite. The delamination is one of the major lack of the composite due to the poor bonding of matrix-fiber interphase (Meshi et al., 2016). The shear modulus is related to the modulus of elasticity in shear which calculated in equation 1 below: 
Table 1. Interlaminar Shear Properties of UHMWPE/HDPE under Different Treatments $( \pm$ Standard Deviation)

\begin{tabular}{|l|l|l|l|l|l|l|}
\hline \multicolumn{1}{|c|}{ Type of Properties } & \multicolumn{3}{|c|}{ Pressure (10 minutes 130 $\left.{ }^{\circ} \mathbf{C}\right)$} & \multicolumn{3}{c|}{ Duration (50 bar 130 $\left.{ }^{\circ} \mathbf{C}\right)$} \\
\cline { 2 - 7 } & 50 bar & 100 bar & 165 bar & 10 minutes & 24 hours & 48 hours \\
\hline ILSS (MPa) & $5,17 \pm 0,04$ & $5,46 \pm 0,08$ & $6,62 \pm 0,07$ & $5,17 \pm 0,04$ & $5,68 \pm 0,01$ & $6,01 \pm 0,10$ \\
\hline Shear Modulus (MPa) & $99,2 \pm 7,18$ & $110,01 \pm 8,64$ & $199 \pm 27,63$ & $99,2 \pm 7,18$ & $52,25 \pm 2,38$ & $66,2 \pm 6,90$ \\
\hline
\end{tabular}

$$
G=\frac{3 F S}{5 b h d}
$$

Where $F=$ the Force (Load) at the fracture point $(\mathrm{N}) ; b=$ width of the sample $(\mathrm{m}) ; h=$ thickness of the sample $(\mathrm{m}) ; S=$ span length $(\mathrm{m})$; and $d=$ deflection $(m)$.

The results of interlaminar shear tests are shown in Table 1. According to Table 1, the interlaminar shear strength increased the same as the bending strength where the higher the pressure and the longer the duration, the higher the value of interlaminar shear strength. Nevertheless, the shear modulus in duration variation declined from $99,2 \mathrm{MPa}$ to $52,25 \mathrm{MPa}$ (24 hours) and 66,2 MPa (48 hours).

\section{Mechanical Properties Relevant to Curing Treatment}

Based on both variations of pressure and duration of curing, to determine the significance of any difference between treatments, one-way analysis of variance (ANOVA) tests were conducted. Furthermore, the relationships between pressure, duration of curing, and mechanical properties were calculated using a Pearson correlation coefficient $(r)$.

Different curing pressure and duration influenced the bending and shear properties (Figures 1, 2, and Table 1). The bending strength increased as the pressure added and duration extended $(r=0,976$ for pressure and $r=0,930$ for duration). Similarly, the bending modulus increased as the pressure and duration increased ( $r=0,895$ for pressure and $r=0,999$ for the duration). The bending strength was significantly higher when the pressure rose $(p<0,05)$. On the other hand, the bending modulus in Figure 1 was not significantly different $(p>0,05)$, presumably because the UHMWPE/HDPE composite outer surface had the same elasticity under different pressure.

Table 1 presents the interlaminar shear behavior of UHMWPE/HDPE composite under variation of curing treatment; they are significantly different $(p<0,05)$, with 165 bar of pressure having the highest interlaminar shear properties, both strength, and modulus. This is due to the similar character of UHMWPE and HDPE where both materials are ductile and tend to be elastic when they are combined, thus the laminates blended well. Moreover, the relation of both shear properties to the increasing pressure was positive since $r=0,980$ for the ILSS and $r=$ 0,939 for the shear modulus. Nevertheless, this does not apply to shear modulus relation to the curing duration. The correlation coefficient $(r)$ of shear modulus-duration was $-0,565$ means there was a moderate negative correlation between them as the longer the duration the shear modulus tends to decrease. Evidently, because the layers could not stand the longer curing process thus it reduced the elasticity between the layers of composite.

With the value of bending and shear properties of the UHMWPE/HDPE composite, it is known that this material is not applicable yet for a large scale wind turbine. The requirement of a wind turbine must be strong in bending because the wind turbine is primarily loaded in bending (van der Zee et al., 2017). Even the study of Young (2017) discovered that HDPE has an ability to face a wide range of wind since the blades can be bent in high winds under extreme temperature, but the reality is the GFRP (Glass Fiber Reinforced Plastic) still significantly higher than UHMWPE/HDPE composite where GFRP for wind turbine has a bending modulus of $43 \mathrm{GPa}$ and shear modulus of $14 \mathrm{GPa}$ (Ullah et al., 2020) while UHMWPE/HDPE in this study has less than 30 $\mathrm{GPa}$ and $200 \mathrm{MPa}$ for bending and shear modulus, respectively.

\section{CONCLUSIONS}

This study aims to evaluate the mechanical properties of high-performance fiber composite, especially UHMWPE/HDPE, to be an alternative to windmill turbine main material. The results of 
the study indicate that the differences in pressure and duration of the curing process to the mechanical properties were statistically significant. Although this preliminary study result is promising, but under higher pressure and longer duration than this study, the samples might be defective and lower their strength. To reach the requirement of windmill turbine material, it is necessary for further research to investigate the molecular area of UHMWPE/HDPE composite and enhance the strength from it.

\section{REFERENCES}

ASTM International. (1995). ASTM D 2344, Standard Test Method for Apparent Interlaminar Shear Strength of Parallel Fiber. $84,6-8$

ASTM International. (2003). Designation: D790 02 "Standard test methods for flexural properties of unreinforced and reinforced electrical insulating materials." Annual Book of ASTM Standards, 14, 146-154. www.astm.org

Byrne, C. (2000). Technical textiles market-an overview. Handbook of Technical Textiles, 123.

Dai, J., Hu, Y., Liu, D., \& Long, X. (2010). Calculation and characteristics analysis of blade pitch loads for large scale wind turbines. Science China Technological Sciences, 53(5), 1356-1363.

European Commission. (1997). Energy for the future: renewable sources of energy - white paper for a community strategy and action plan. COM, 599.

Fung, W. (2000). Textiles in transportation. Handbook of Technical Textiles, 490-528.

Hidayah, F. N. (2019). Interlaminar Shear Behaviour of UHMWPE ( Ultrahigh Molecular Weight Polyethylene) Based Composites with Different Matrixes. 1, 1-9.

Kim, C., Kim, K., Kim, H., Paek, I., Yoo, N., Nam, Y., Campagnolo, F., \& Bottasso, C. (2012). A method to estimate bending moments acting on a wind turbine blade specimen using FBG sensors. International Journal of
Precision Engineering and Manufacturing, 13(7), 1247-1250. https://doi.org/10.1007/s12541-012-01664

Leary, K. O., Pakrashi, V., \& Kelliher, D. (2019). Optimization of composite material tower for offshore wind turbine structures. Renewable Energy, 140, 928-942. https://doi.org/10.1016/j.renene.2019.03.1 01

Meshi, I., Amarilio, I., Benes, D., \& Haj-Ali, R. (2016). Delamination behavior of UHMWPE soft layered composites. Composites Part B: Engineering, 98, 166-175. https://doi.org/10.1016/j.compositesb.201 6.05 .027

Murray, R. E., Roadman, J., \& Beach, R. (2019). Fusion joining of thermoplastic composite wind turbine blades: Lap-shear bond characterization. Renewable Energy, 140, 501-512.

https://doi.org/10.1016/j.renene.2019.03.0 85

Nachtane, M., Tarfaoui, M., Mohammed, M. A., Saifaoui, D., \& Moumen, A. El. (2020). Effects of environmental exposure on the mechanical properties of composite tidal current turbine. Renewable Energy, 156, 1132-1145.

https://doi.org/10.1016/j.renene.2020.04.1 26

Overgaard, L. C. T., Lund, E., \& Thomsen, O. T. (2010). Structural collapse of a wind turbine blade. Part A: Static test and equivalent single layered models. Composites Part A: Applied Science and Manufacturing, 41(2), 257-270.

Ramirez-Tejeda, K., Turcotte, D. A., \& Pike, S. (2016). Unsustainable Wind Turbine Blade Disposal Practices in the United States: A Case for Policy Intervention and Technological Innovation. NEW SOLUTIONS: A Journal of Environmental and Occupational Health Policy, 26(4), 581-598. https://doi.org/10.1177/104829111667609 8

Scott, R. A. (2000). Textiles in defence. Woodhead Publishing, Cambridge, UK.

Theile, B., \& Hoffmann, A. (2019). Rotor Blade 
Element For A Wind Turbine, Rotor Blade, And A Production Process Therefor And Wind Turbine With Rotor Blade (Patent No. US010344738B2).

Ullah, H., Ullah, B., \& Silberschmidt, V. V. (2020). Structural integrity analysis and damage assessment of a long composite wind turbine blade under extreme loading. Composite Structures, 246(April), 112426. https://doi.org/10.1016/j.compstruct.2020. 112426

van der Zee, T., de Ruiter, M. J., \& Wieling, I. (2017). The C-Tower project-A composite tower for offshore wind turbines. Energy Procedia, 137, 401-405.

Verma, A. S., Vedvik, N. P., Haselbach, P. U., Gao, Z., \& Jiang, Z. (2019). Comparison of numerical modelling techniques for impact investigation on a wind turbine blade. Composite Structures, 209, 856-878.

Williamson, L. (1997). WIND TURBINE (Patent No. US005669758A).

Young, A. C., Goupee, A. J., Dagher, H. J., \& Viselli, A. M. (2017). Methodology for optimizing composite towers for use on floating wind turbines. Journal of Renewable and Sustainable Energy, 9(3), 33305.

Young, G. L. (2017). High torque wind turbine blade, turbine, generator, and associated systems and methods. Google Patents.

Zuo, Y., Montesano, J., \& Singh, C. V. (2018) Assessing progressive failure in long wind turbine blades under quasi-static and cyclic loads. Renewable Energy, 119, 754-766. 
Rekayasa, 13 (3): 2020 | 225 